\title{
O discurso teórico nas Relações Internacionais
}

\author{
Marcelo José Ferraz Suano*
}

\section{O problema relações internacionais: a questão das teorias}

Observa-se acerca dos estudos das relações internacionais ${ }^{1}$ confusões que perseguem os pensadores em suas reflexões, graças às quais normalmente não se sabe a que eles se referem quando discorrem sobre o assunto.

É normal percebermos nos trabalhos da área, questões metodológicas que ainda não foram equacionadas, mesmo que durante um certo período do século XX, principalmente nas décadas dos 50 e 60, vários pesquisadores tenham tentado contorná-las quando se recusaram a apresentar uma explicação geral para o fenômeno. Buscavam abordagens circunscritas a certos problemas dentro do campo e não uma explicação totalizada e analisavam as questões prendendo-as às metodologias das ciências do comportamento. Objetivavam, com isso, dar um tratamento que, das suas perspectivas, era a única forma de garantir um padrão científico para a disciplina.

* Doutor e Mestre em Ciência Política pela USP. Pesquisador do Núcleo de Estudos da Paz, da Pucrs e professor de Relações Internacionais da Faculdade Tancredo Neves. E-mail: msuano@ig.com.br

1 Adota-se aqui padrão de escrever com maiúscula sempre que se referir à disciplina Relações Internacionais e com minúscula quando a referência for ao objeto relações internacionais.

\begin{tabular}{|l|l|l|l|l|l|} 
Civitas & Porto Alegre & v. 5 & n. 2 & jul.-dez. 2005 & p. 245-274 \\
\hline
\end{tabular}


Recentemente, um interessante capítulo escrito por Williams Gonçalves no livro $O$ Século Sombrio ${ }^{2}$ apareceu iluminando a reflexão que precisa ser realizada acerca de uma questão que propomos tratar e consideramos que seja essencial ao campo das Relações Internacionais, pois permite-nos entender o desenvolvimento da disciplina: que modalidade de discurso está sendo apresentado quando alguém se pronuncia acerca das questões da área.

Ele nos apresenta uma proposta de entendimento de certos problemas que são fundamentais para que se possa respondê-la e pretendemos desenvolver suas reflexões em alguns aspectos. Para melhor tratar de tais assuntos, é interessante que se explique a contribuição desse autor, o que servirá de ponta de lança para o que se propõe.

A primeira grande percepção apresentada por Williams Gonçalves no seu texto diz respeito ao fato de, ao contrário das demais ciências, Relações Internacionais sofrerem de um problema terminológico que produz graves conseqüências ao entendimento de seu campo de conhecimento: o objeto estudado tem o mesmo nome da ciência que o estuda, ou seja, a disciplina Relações Internacionais estuda as relações internacionais. Percebemos que essa sobreposição de termos traz consigo grandes transtornos, principalmente aos leitores dos assuntos da esfera internacional que são obrigados a tomar contato com o tema, mas não são iniciados na sua linguagem, nem na história da disciplina.

O autor adentra o problema apresentado-nos que são três abordagens que precisam ser feitas sobre o termo "relações internacionais": a abordagem do objeto de estudo; aquela da disciplina e a que se aplica ao conjunto teórico.

No primeiro caso, mostra-nos que a grande dificuldade em tratar do objeto decorre de sua imaterialidade, pois ele se constitui de uma abstração, um produto do pensamento, que leva a uma certa arbitrariedade na sua definição quando realizada pelos estudiosos do assunto.

Segundo afirma, essa arbitrariedade não implica numa aleatoriedade. Embora o objeto não se evidencie e exija do intelectual que observa as rela-

2 Livro organizado por Francisco Carlos Teixeira da Silva, que tenta apresentar uma história do século XX da perspectiva das Relações Internacionais a partir de uma coletânea de textos de vários autores. 
ções internacionais que ele as destaque de tudo o mais com uma contribuição individual, ao fazê-lo, vê-se obrigado a admitir certas constantes para que se evite confundi-la com outros fenômenos. Essa obrigatoriedade já evidencia a existência de uma área com elementos distintos dos demais campos do conhecimento humano. Assim, o pensador sempre terá que dar uma contribuição individual ao isolar o objeto, mas não o fará com independência a ponto de não ser necessário apresentar elementos cuja presença seja obrigatória em qualquer definição que se venha elaborar acerca dele. Ou seja, é possível perceber que o objeto tem uma especificidade sua, configurando-se como uno, embora, internamente, ele se construa de múltiplas formas.

Para contornar essa dificuldade, Williams Gonçalves reúne as definições de relações internacionais em dois grandes grupos. Quanto ao primeiro, interpretamos que o autor considera-o como sendo aquele que trata de fenômenos concernentes a relações entre atores que negociam no mundo, ${ }^{3}$ "incluindo fenômenos dos diversos domínios da vida em sociedade e as relações tanto de conflito como de cooperação" sendo possível que cada um desses fenômenos venha a ser objeto de análise das Relações Internacionais (Gonçalves, 2004, p. 28). Quanto ao segundo grupo, diz-nos que trata das relações entre os Estados, apresentando-se a realidade das relações internacionais pelos "conflitos entre os interesses respectivos a cada Estado. Assim, os temas são concebidos como produtos das relações diplomáticas, militares e estratégicas que os Estados [...] estabelecem entre si” (Gonçalves, 2004, p. 28).

Segundo interpreta, é possível evitar a aleatoriedade pela idéia de "anarquia" que perpassa a realidade das relações internacionais. Entendendo-se a "anarquia" no contexto hobbesiano, interpretamos que ela se torna o elemento unificador dos fenômenos existentes nas relações internacionais por ser uma condição presente na realidade de cada um deles, qualquer que seja o comportamento, ou "sub-fenômeno" isolado, que possa ser identificado pelo especialista como o objeto da disciplina. Ou seja, qualquer fenômeno que se

3 O autor lista os seguintes fenômenos: paz e guerra; armas nucleares e desarmamento; imperialismo e nacionalismo; as relações assimétricas entre sociedades ricas e sociedades pobres; preservação do meio ambiente; combate ao narcotráfico; combate ao terrorismo internacional; defesa dos direitos humanos; influência das instituições religiosas; organizações internacionais; processos de integração regional; formação e fragmentação dos estados; comércio e ação das corporações multinacionais; raça e gênero em todo o mundo; desenvolvimento e transferência de tecnologia; globalização. 
isole dentro do campo, sempre terá de ser pensado no contexto de uma anarquia que condiciona as formas de relação entre os atores que atuam no campo dito internacional.

Tomando a anarquia como pano de fundo, pode-se dizer que será possível pensar um espaço autônomo, mesmo que cada escolha incorra em conseqüências específicas de ordem teórica e metodológica, que derivam do fato de sempre ser necessário pressupor um constructo teórico para mostrar a forma como se escolheu um aspecto do objeto relações internacionais e não outro, ou como se articula uma certa definição com a própria realidade. Ademais, acrescentamos que qualquer escolha deverá explicar mais que o subfenômeno dentro do fenômeno. Terá de explicar, também, as razões da escolha de um ou vários aspectos, dentre tantos outros, quase como se em cada teorização, o estudioso fosse obrigado a refundar a disciplina.

$\mathrm{O}$ que foi dito refere-se ao problema do objeto. Quanto à abordagem da disciplina, Williams Gonçalves esclarece-nos que seu surgimento ocorreu em virtude da Primeira Guerra Mundial, quando, ao fim do conflito, a opinião pública exigiu a punição dos culpados pela guerra e a criação de condições para que não mais ocorresse outro conflito de tais dimensões. Assim, surgiu a necessidade de se produzir conhecimentos sobre a realidade das relações internacionais, sendo criadas, nesse período, cátedras da área em alguns países. ${ }^{4}$

É importante considerarmos em sua exposição o fato de ter destacado a novidade que se produziu no estudo do tema no pós-1919 quando se buscou um objeto que lhe desse autonomia: "as abordagens das relações internacionais passaram a se dar não mais a partir do Direito, da Diplomacia, ou da História Diplomática" (Gonçalves, 2004, p. 28). Destacamos que esse elemento é importante, pois traz à tona a percepção da necessidade de observar as relações internacionais de uma perspectiva que vá além da narrativa, mesmo que explicativa, ou da descrição, buscando o entendimento de um comportamento que apresenta certas regularidades, o que permitirá a sua "compreensão", ou, em muitos casos, até mesmo a identificação de relações de causa e efeito.

4 De acordo com o autor, foi criada, em 1919, na Universidade de Gales (Aberyswyrth), a cátedra Woodrow Wilson de Política Internacional e, em 1920, na Inglaterra, o Royal Institute of International Affairs (Gonçalves, 2004, p. 30).

5 Problema que, destacamos, continua relevante hoje em dia, pois ainda não se pode falar com precisão qual é. 
Outra percepção do autor que muito contribui para os estudiosos e leitores do tema está em mostrar que é tarefa da disciplina Relações Internacionais realizar uma visão integrada do meio internacional que vá além das visões parciais da Economia Internacional, do Direito Internacional, da História Internacional e da Política Internacional. ${ }^{6}$

Mostra-nos, ainda, algo que também irá contribuir muito para nossa reflexão: o fato de não existir uma classificação das teorias existentes que seja comum. Isso tem ocorrido desde o momento em que começaram a ser apresentadas as teorias das relações internacionais, divergindo os paradigmas e as formas de estabelecê-los. Por isso, cada estudioso da disciplina e de sua história normalmente apresenta uma forma própria de dividir os grupos de teorias e mostrar suas transformações. ${ }^{7}$

Acrescentamos que é perceptível que normalmente cada classificador, que podemos doravante chamar de "taxionomista das teorias das relações internacionais", ou simplesmente "taxionomista", escolhe um critério para apresentar sua listagem de teorias, ou adota uma perspectiva que lhe permita situar o seu posicionamento acerca do que considera ser o objeto de estudo das Relações Internacionais e, antes de dissertar sobre o tema, apresenta o estado da arte e por quais aspectos se assemelham os grandes teóricos. ${ }^{8} \mathrm{Ou}$ seja, raramente a classificação elaborada por um autor está desprovida da intencionalidade de tentar mostrar sua percepção do objeto relações internacionais, o que nos coloca na situação de estarmos adotando uma "escola" quando utilizamos um "taxionomista" para entender a evolução do campo de estudos. Em termos do conhecimento da disciplina essas contribuições de Williams Gonçalves são esclarecedoras e nos abrem uma série de portas.

6 É necessário, porém, esclarecer, embora Williams Gonçalves não o faça, que a história internacional, quando não era apresentada como história da diplomacia e/ou a história da política internacional, acabava se resumindo na história do mundo abordando as mudanças políticas que mais interferiram nas transformações das civilizações, ressaltando-se que quase exclusivamente da civilização ocidental, algo que confundiu mais ainda o entendimento do fenômeno relações internacionais.

7 Em seu texto são citados Oloe Waever, Graham Evans e Jeffrey Newham, Charles Kegley Jr., Eugene Wittkopf, Robert Jackson e George Sorensen e Hedley Bull, com suas respectivas classificações.

8 Casos também de Stanley Hoffmann, Marcel Merle, Phillippe Braillard, Martin Griffiths, Dougherty e Pfaltzgraff Junior, outros autores que não são citados por Williams Gonçalves e acrescentamos em sua lista. 
Completando os esclarecimentos dos tópicos do seu texto, é necessário que se fale sobre a terceira abordagem que apresenta sobre o termo relações internacionais: a questão do conjunto teórico. Como bem destaca, ao analisar textos de alguns autores, sendo muitos deles "taxionomistas", identifica que a evolução teórica se deu em torno de "Grandes Debates" entre teorias emergentes e teorias dominantes que se processaram ao longo do século XX, dividindo-a em quatro fases que percorreram esse século, do surgimento da disciplina até o momento atual: o primeiro, teria ocorrido ao longo da década de 30 , opondo a corrente liberal-idealista ao emergente realismo; o segundo deuse no final dos anos 50, quando ocorreu discussão de ordem metodológica opondo os tradicionalistas ${ }^{9}$ e os bahavioristas $;{ }^{10}$ o terceiro deu-se na década dos 70, opondo realistas e pluralistas, foi o "Debate dos Paradigmas"; e, por fim, o atual que, segundo afirma, é difícil de ser resumido devido a sua ambigüidade conceitual, sabendo-se que o alvo das críticas é o realismo, que tem como opositores as posições elaboradas pela Teoria Crítica, pelo PósModernismo e pelo Feminismo.

O trabalho de Williams Gonçalves tem a grandeza de sintetizar para os leitores dos temas internacionais o "estado da arte" da disciplina. Nessa questão dos "grandes debates", sua abordagem aproxima-se da realizada por Theodore Columbus, que, em 1986, escreveu Introdution to international relations: "power and justice". Esse autor usa categorias similares distinguindo-se de Williams Gonçalves pela menor abrangência nas comparações, inclusive reduzindo os debates a três momentos e não a quatro, o que se explica pela época em que foi escrito.

Para os objetivos desse artigo, o que se apresenta com grande importância é a percepção da distinção das abordagens do objeto, da disciplina e da evolução teórica, pois essa distinção é real e ela nos obriga a sempre identificar qual o universo da nossa análise quando nos pronunciamos e também a delimitar aquilo em que se está centrando foco para evitar que se incorra em tratar de um assunto quando se está tratando de outro. Ou seja, não se pode

9 Que reunia liberal-idealistas e realistas como compondo um mesmo grupo.

10 Deve-se acrescentar que o termo foi adotado pelos pesquisadores que, buscando dar caráter científico à disciplina, limitavam suas pesquisas a determinados comportamentos do campo das relações internacionais e adotavam as metodologias das ciências do comportamento, daí behavioristas. 
esquecer que, no limite, sempre devemos ter em mente que são três histórias que precisam ser observadas como distintas, embora haja conexão entre elas. Inicialmente, temos que levar em conta a história do objeto, ou seja, a história do fenômeno, a qual podemos definir como sendo a história daquilo que entendemos como sendo as relações internacionais, que, graças aos problemas que foram citados, comumente se apresenta de formas variadas. Tal variação se dá não pela mudança da metodologia historiográfica adotada ou pelas diferentes perspectivas na bordagem do objeto em seu percurso histórico, mas, como foi referido, devido à nebulosidade do próprio objeto. Assim, teremos histórias das relações internacionais distintas, não raro dissolvendose no contexto da história das civilizações, ou confundindo-se com ela, e usando categorias e conceitos exclusivos para uma apresentação, que não são aplicados em outras tentativas de mostrar a evolução, ou a transformação do fenômeno ao longo do tempo. Em síntese, a historicização do fenômeno acaba implicando na defesa de uma percepção do objeto.

Há, também, a história da disciplina, ou seja, a história da ciência Relações Internacionais no seu percurso de autonomização, processo que ainda hoje persiste, e se iniciou no pós-1919. Podemos dizer que para o estudioso do campo e, principalmente, para o universitário que busca nos cursos de Relações Internacionais uma profissão, este é um problema que se tem mostrado angustiante.

Relatar quando começou o esforço de criar uma ciência das relações internacionais e quais são os textos que têm a pretensão de apresentar uma teoria científica sobre elas não tem sido difícil. O problema está em conseguir demonstrar que a disciplina tem um estatuto científico. Não são raras as afirmações de que Relações Internacionais ainda não passa de uma elaborada elucubração filosófica, pois, além de não conseguir usar um método que seja genuinamente científico, ou que esteja mais próximo daquilo que a Filosofia da Ciência contemporaneamente chama de método científico, não consegue cumprir o que se exige, ou se espera de uma ciência: que explique um fenômeno; que apresente a forma de controlá-lo; que se consiga fazer previsões acerca do seu comportamento. Isso implica em que não basta apenas definir o objeto e explicá-lo, pois, assim, apenas teríamos as condições necessárias, mas não suficientes para que a disciplina seja considerada um conhecimento científico. 
Como diria Hempel, dentre os fatores que levam o homem a realizar pesquisa científica estão a curiosidade intelectual e o caráter prático, significando isso que

[...] o Homem [sic] procura, constantemente, melhorar a posição estratégica em que se situa face ao mundo em que vive e, para tanto, busca meios eficazes de prever o curso dos acontecimentos que têm lugar à sua volta e, sempre que possível, tenta controlá-los para disso retirar proveito (Hempel, 1971, p. 159).

Ainda segundo Hempel, esse comportamento gera um tipo de explicação com o intuito de efetuar previsões acerca do fenômeno observado, de onde propõe que seja possível afirmar que se um acontecimento específico causa um outro acontecimento, pode-se concluir que o surgimento do primeiro acontecimento será sempre acompanhado do segundo, ou seja, temos explicações dedutivas, importando saber que são relevantes não apenas as deduções dos casos particulares, mas as deduções em relação as regularidades expressadas por leis gerais (Hempel, 1971, p. 162).

Nesse sentido, como ainda nos diz, a "uniformidade de uma lei é explicada mostrando-se que ela vigora [...] como conseqüência de outras leis mais gerais, ou de princípios teóricos mais fundamentais e amplos" (Hempel, 1971, p. 163).

\section{Disso conclui que}

desenvolver teorias que explicarão dessa maneira (dedutivamente) as regularidades expressas por leis empíricas é um dos principais empenhos do trabalho científico e muitos cientistas sustentarão que só se atinge compreensão científica genuína quando se pode elaborar teorias explicativas (Hempel, 1971, p. 163).

A busca desse apoio em leis abrangentes se dá tanto nas explicações que se baseiam em leis universais quanto em explicações que se baseiam em leis probabilísticas, explicações que têm ganhado espaço no campo científico. Ou seja, "todas são asserções alicerçadas em leis abrangentes, de tipo dedutivo ou probabilísitico". E, também muito importante, "uma explicação científica adequada não apenas alarga, mas aprofunda o entendimento a respeito de determinado campo de investigação" (Hempel, 1971, p. 163).

Há o consenso de que esse modelo de explicação científica tem como base as ciências da natureza, trazendo críticas quanto a sua aplicação às ciências humanas, quando ao invés de se requerer que uma ação seja explicada "por 
subsunção dedutiva ou probabilística a partir de leis gerais", seriam usadas razões. Ainda assim, essas razões são, "fundamentalmente, explicações por subsunção a leis abrangentes" (Hempel, 1971, p. 169), retornando-se ao modelo proposto.

Ernest Nagel também chega à conclusão semelhante acerca da ciência ao afirmar que

há três aspectos da Ciência atual que [...] nos auxiliam a definir-lhe a natureza e os objetivos [...]. 1. [...] permite o controle da natureza. 2. [...] propõe atingir um conhecimento sistemático e seguro, de sorte que seus resultados possam ser tomados como conclusões certas a propósito de condições mais ou menos amplas e uniformes sob as quais ocorrem os vários tipos de acontecimentos. 3. [...] seu método de investigação [...] (Nagel, 1971, p. 11-24).

Poderíamos questionar se a disciplina Relações Internacionais teria esta pretensão. A resposta é sim. Já com Edward Hallet Carr, um dos seus pais construtores, quando escreveu Vinte anos de crise: 1919-1939, tem-se explícito que o surgimento da disciplina se deu com o intuito entender e explicar a realidade para interferir nela controlando-a, uma vez que se queria produzir uma "segurança coletiva". Todo o seu livro tenta mostrar os elementos que permitiriam produzir a ciência Relações Internacionais, embora ainda se pensasse como equivalentes os problemas de relações internacionais e de política internacional.

Podemos, assim, concluir afirmando que, queira ou não, a questão da disciplina Relações Internacionais é a questão da sua autonomia, ou melhor, é o relato histórico da busca dos elementos que possibilitam torná-la uma ciência, para cumprir os objetivos que se propõe com o conhecimento científico. Isso não é o equivalente à compilação das teorias apresentadas cronologicamente.

A terceira história é aquela que denominamos "história das teorias", que podemos entender como a história das explicações sobre a forma como se dão as relações internacionais. A teoria tem a pretensão de explicar a ordem mundial e apresentar os indicativos de se preservar a paz no sistema. Esse exercício não corresponde ao período do surgimento da disciplina, pois já 
havia tentativas de explicação de questões do poder relativos ao campo internacional antes do surgimento da disciplina em si, é o caso da geopolítica. ${ }^{11}$

A necessidade de se ter consciência dessas distinções se dá pela arbitrariedade que foi identificada no exercício de abordagem e circunscrição de um objeto de análise que possa ser denominado relações internacionais. Talvez esse seja o problema que escapa pelas mãos: o objeto relações internacionais constitui-se de um conjunto de fenômenos, os quais podem ser tratados individualmente e cada um deles ser confundido ou tomado como o todo. E, para piorar, também pode se constituir da costura tentada por um teórico sobre um conjunto de fenômenos isolados. Quanto maior for a pretensão de abrangência da teoria, maior será o número de fenômenos agrupados e maior o exercício da costura teórica na qual são apresentadas as regularidades que permitem afirmações com pretensão científica. Acrescentando-se, também, os casos em que se tenta circunscrever o objeto por meio da identificação de sua essência.

Percebemos, então, que tudo circula a questão da dificuldade de se construir uma disciplina científica sobre um objeto tão nebuloso. Desse ponto podemos dar um outro salto reflexivo.

\section{A interpretação da expressão "relações internacionais": entendendo o fenômeno}

O fato de não conseguirmos isolar um objeto preciso que possa ser aceito de forma semelhante pelos pesquisadores em Relações Internacionais, não impede que o pensador do campo realize um trabalho intelectual. Mas, aí também temos tipos de reflexão distintas que são realizadas quando se aborda fenômeno e, para tanto, torna-se necessário esboçarmos algumas definições sendo importante que esclareçamos como podemos entender a expressão "relações internacionais". ${ }^{12}$ São dois termos que devem ser explicados, aceitando-se que o signo "inter" é intuitivo e significa apenas entre.

11 Embora muitos autores não a tomem como uma teoria das relações internacionais, mas sim uma teoria do poder, algo com o qual concordamos, ainda assim tentou-se com ela dar conta de um modelo de entendimento das relações entre os Estados, o que acaba por atribuir-lhe um estatuto de teoria das relações interestatais.

12 Aqui deixaremos de lado a discussão de se essa forma de entender a expressão "relações internacionais" é apenas mais uma abordagem realista, pois estenderia muito a discussão do tema e estaria além do escopo deste artigo. 
O primeiro é o termo relações. ${ }^{13}$ Embora aparentemente banal, relação não é um termo tão intuitivo quanto a primeira vista possa parecer, necessitando que se o compreenda. Relações, aqui, deve ser entendida como contatos constantes visando alcançar interesses por meio de trocas, sejam essas trocas de que natureza forem: econômicas, culturais, políticas, militares etc. A constância dos contatos é essencial para que se possa estabelecer uma relação entre partes que se buscam, ou são obrigadas a se contatarem em função de necessidades específicas de cada uma, seja em função de carências próprias que a obrigam a comerciar com os vizinhos, seja em função da incapacidade de livrarem-se uma da outra na disputa por bens, ou na ocupação de um espaço contíguo. Isso traz à tona o fato de que as relações entre essas partes existe em função da capacidade de comunicação e da evolução tecnológica de uma época, pois, somente em função da capacidade de trocar informações em tempo hábil, bem como da capacidade do transporte é que o contato tangencial poderá se tornar uma relação.

Constatando-se o estabelecimento de relações entre partes que se procuram, ou são obrigadas a se contatarem, percebemos que o problema principal transporta-se para a identificação de quem são as partes que se relacionam produzindo interações e se relacionando. Neste momento é que percebemos algumas das grandes razões pelas quais o objeto relações internacionais é tão nebuloso. O problema está na palavra internacional, que se compõe de duas partes: a primeira inter não é problema, como já afirmamos anteriormente, mas a segunda, nacional, não corresponde à realidade dos fatos identificados, e produz distúrbios de concepção que nos levariam a pensar que relações internacionais são um fenômeno recente da realidade humana. Ademais, o termo nacional, derivado de nação, leva o iniciante na disciplina a pensar que o ator das relações internacionais, corresponde a um conceito que, além de construído na modernidade, quando é usado tenta designar um todo homogêneo que se expressa por meio de seus representantes. Se observarmos mais atentamente, mesmo quando o termo estava sendo desenvolvido, ao ser usado no contexto das relações internacionais ele queria designar coisa distinta do seu próprio significado, não é a toa que seu substituto imediato é o temo Estado, uma vez que intuitivamente era a esse elemento que se estava a referir.

13 Para não problematizar excessivamente, também não refletiremos sobre o termo relação no conceito weberiano de relação social. 
Mas isso é real? O próprio termo Estado também se refere à construção de algo recente. Como nos diz Norberto Bobbio, é um termo que foi usado para designar uma nova realidade, para dar conta de uma nova construção das relações de poder e de organização das sociedades (Bobbio, 1990), que no limite veio para designar um tipo de "organização política" que nasce na idade moderna.

Esse é um problema extremamente nebuloso para o entendimento. Diríamos que a questão está em que não devemos nos referir ao Estado, mas, como nos informa Bobbio, à "organização política", que se configura nas instituições que organizam as relações de poder de uma sociedade, pois é nisso que pensamos quando falamos em Estado, percebendo que este termo apenas se refere à feição moderna de um fenômeno que sempre se produziu, embora se saiba que o Estado Moderno não tem continuidade com os tipos de organizações políticas que se deram anteriormente na história. É algo específico de uma época, que surge para dar conta de novas realidades derivadas do esgotamento do mundo feudal.

Mas, ainda assim, o termo não traz esclarecimentos. Usar o Estado para significar a parte que faz relações internacionais traz alguns inconvenientes. Primeiro, pode nos levar a pensar que o fenômeno nasce com a modernidade e, além disso, se ele significa um tipo de organização política, a própria expressão que o substitui não tem, de imediato, o significado que se pensa intuitivamente: "país". Ou seja, é necessário que busquemos maior precisão para entendermos a questão do Estado como aquela parte que estabelece contatos nas relações internacionais.

Da própria análise de Bobbio podemos, então, concluir que quando pensamos em Estado no sentido lato, pensamos em unidades políticas, ou seja, em tipos de organização das relações de poder e organização da sociedade, que Bobbio denominou como organizações políticas. Se quisermos designar o fenômeno no sentido estrito, teremos de adjetivá-lo. Dessa forma, poderíamos usar o termo para designar o fenômeno unidade política ao longo do tempo.

Ainda assim, teremos problemas na identificação das partes que se relacionam no campo internacional. Seriam as unidades políticas, ou seja, os Estados, os elementos que tecem relações internacionais? Apenas os realistas, tanto o grupo radical, quanto o grupo moderado, consideram que sim. Nesse 
sentido, poderíamos dizer que somente um grupo, talvez o mais importante, quando não o mais barulhento, considerariam que são as unidades políticas as partes que estabelecem relações no cenário internacional.

Percebemos que faltam ainda vários elementos para um bom entendimento da expressão relações internacionais, pois ao longo do último terço do século XX observou-se o surgimento de vários outros tipos de atores que passaram a se apresentar como partes relacionando-se no cenário internacional, e agindo além das realidades circunscritas ao interior das unidades políticas. Nesse sentido, no âmbito da teorização, é preferível usar um termo mais genérico para tentar compor uma interpretação mais adequada às transformações que se deram ao longo do tempo e produziram alterações no próprio fenômeno relações internacionais. Talvez, a forma de melhor expressar o significado da expressão relações internacionais seja: contatos permanentes estabelecendo uma rede de relações, visando alcançar interesses por meio de trocas (sejam de quais naturezas forem essas trocas: econômicas, políticas, culturais, militares etc.) entre atores cujos tipos e quantidades se alteraram ao longo da história em função de uma série de aspectos (econômicos, científicos, tecnológicos, geográficos, políticos etc.) que lhes deram poder de ação em um cenário ampliado, capacitando-os a influenciar, ou determinar a conduta de outros atores.

Essa forma de entender a expressão parece-nos mais adequada para limpar o terreno do fenômeno. Restam, contudo, alguns outros problemas que precisam ser tratados para que análise da expressão não caia no vazio mostrando uma espécie de ausência de especificidade do fenômeno internacional. Afinal, em que medida essa "definição" aqui apresentada o distinguiria do fenômeno social como um todo, ou o distinguiria do problema do relacionamento entre atores dentro de uma unidade política? Afinal, nas sociedades contemporâneas, mesmo o aspecto militar tem se mostrado como fator relevante, vide a atuação do crime organizado, bem como dos grupos sociais em processo de "retribalização".

Se quisermos buscar o elemento distintivo, teremos que completar a análise da expressão acrescentando que esses atores constituem uma estrutura, cuja principal característica é a ausência de um poder que se sobreponha a eles e, por isso, define os condicionantes de suas ações, com poder de punição dos atos transgressores. Ou seja, como foi afirmado por Williams Gonçalves, a anarquia, no contexto hobbesiano, é o elemento distintivo que dá unidade ao fenômeno. 
Sendo assim, a única forma de tirarmos do vazio epstemológico a análise e interpretação feita da expressão será definindo o espaço em que se constituem esses contatos. Pode parecer banal, mas, afinal de contas, qual é o espaço internacional? Normalmente, para o público contemporâneo, quando se fala desse ambiente todos pensam como sendo o mundo. Ledo engano, que traz mais nebulosidade para o fenômeno, pois um olhar na história mostra que a sobreposição do mundo com o ambiente internacional é uma construção que vai começar nos grandes descobrimentos do final do século XV até se constituir, definitivamente, ao longo do século XIX e, por força do hábito, acabamos igualando um conceito geográfico a um conceito de outra ordem, predominantemente político. Talvez, porque a realidade internacional só se concretiza diante da realidade geográfica em que ela é efetivada, mas, como foi dito, nem sempre esse ambiente se deu integrando o mundo como um mundo. Durante grande parte da história foram porções geográficas do mundo os espaços em que se davam os contatos entre os atores que constituíam as relações internacionais, ou seja, os espaços internacionais. Mas de tão óbvio, parece que esse acontecimento tem sido ignorado.

Conseguindo evitar a armadilha do uso de um termo inadequado para expressar realidades diversas, é possível compreender o espaço internacional pelo tipo de estrutura que os contatos entre os atores constituem. Poderíamos dizer que a análise da expressão se completaria dizendo que "relações internacionais" são contatos permanentes estabelecendo uma rede de relações, visando alcançar interesses por meio de trocas (sejam de quais naturezas forem essas trocas: econômicas, políticas, culturais, militares etc.) entre atores cujos tipos e quantidades se alteraram ao longo da história em função de uma série de aspectos (econômicos, científicos, tecnológicos, geográficos, políticos etc.) que lhes deram poder de ação em um cenário ampliado, capacitando-os a influenciar, ou determinar, a conduta de outros atores e constituindo um sistema internacional.

Aqui, somos obrigados a realizar duas reflexões: primeiro, por que usar o conceito de "sistema internacional" e não "sociedade internacional" e, depois, o que podemos entender por "sistema internacional".

Como diria Martin Griffiths ao explicar os autores que adotam o conceito de sociedade internacional, “a expressão 'sociedade internacional' implica que, apesar da ausência de uma autoridade central, os Estados exibem padrões de conduta que estão sujeitos a, e constituídos por, restrições legais e morais" (Griffiths, 2004, p. 215). 
Completando sua análise informa-nos que devemos

[...] pensar nas relações internacionais como uma arena social cujos membros Estados soberanos - se relacionam uns com os outros não apenas como concorrentes por poder e riqueza, mas também como detentores de certos direitos, autoridade e obrigações particulares (Griffiths, 2004, p. 215).

Ou seja, percebemos que, apesar de não termos uma sociedade no conceito clássico, devido à inexistência de um Estado mundial, há regras que regulam o comportamento das unidades soberanas estabelecendo direitos e deveres.

Parece-nos, contudo, que o problema da escolha entre um conceito e outro está a reboque da questão dos tipos de atores que estabelecem as relações internacionais. Normalmente, aqueles que centralizam as atenções nas unidades políticas (Estado) tomando-as como único ator, ou o ator privilegiado, tendem a aceitar o sistema como a realidade constituída pela trama de relações traçadas pelas partes. Já aqueles que identificam atores plurais, não apenas as unidades políticas, acabam por privilegiar que a trama dos atores leva a uma realidade mais ampla, devido a qual a simples idéia do sistema não daria conta. Diríamos que embarcam na tese de que há uma présociedade com trocas econômicas e relações informais que atribuem direitos e deveres antes do surgimento de qualquer pacto, ou contrato, que funde a realidade política strictu senso. Nesse sentido, adotam a idéia de que há uma regulação prévia ao poder político, operando leis e valores e determinando as formas de comportamentos individuais dos vários atores, dentre os quais as unidades políticas (os Estados), que são apenas mais um tipo, que está perdendo cada dia mais força em detrimento dos demais.

O problema está em que a questão da sociedade internacional pode levar a uma fusão entre as dimensões interna e externa extinguindo a realidade internacional, ou daria um grau de complexidade à abordagem do fenômeno que, provavelmente, levaria à perda da autonomia da disciplina.

Dougherty e Pfaltzgraff, por sua vez, nos dão uma boa razão para a escolha da idéia de "sistema internacional":

[...] ele nos proporciona um modelo simples e claro, embora abrangente, que faz corresponder objetivos homogêneos a todos os atores nacionais (embora) [...] por outro lado, também dá azo a imagens simplistas de estados todos iguais, minimi- 
zando as suas diferenças, os seus esforços de sobrevivência e independência dentro do sistema e exagerando o grau em que o sistema determina a conduta das unidades que o constituem (Dougherty e Pfaltzgraff, 2003, p. 42).

Apesar de apresentar esse defeito, percebemos que o conceito de sistema internacional oferece-nos a possibilidade de pensar racionalmente o fenômeno relações internacionais, uma vez que permite articular as ações e identificar as formas de conduta dos atores de quaisquer tipos. Acima de tudo, ele permite buscar a especificidade do fenômeno e pensar a autonomia da disciplina.

Para tanto, podemos, então, adentrar na definição de "sistema internacional" e perceberemos como o conceito permitirá compreender a dimensão das relações internacionais. Utilizaremos Raymond Aron para iniciar nossa reflexão, pois sua definição apresentada em Paz e Guerra entre as Nações é suficientemente ampla para apresentar o conceito e suficientemente sucinta para permitir-lhe inteligibilidade. Ademais, evita problemas como o produzido por Joseph Nye em seu livro Compreender os Conflitos Internacionais: uma introdução à teoria e a análise, que, ao mostrar a realidade das relações internacionais em torno do sistema internacional, informa-nos que ele pode ser o conceito estruturador do fenômeno, mas ao definir os tipos de sistema em função dos critérios imperial, feudal, e anárquico, acabou por colocar as relações internacionais a reboque das relações políticas e a dissolver, assim, o esforço conceitual. Por isso, o trabalho aroniano parece-nos, neste primeiro momento, mais satisfatório. Define o conceito como sendo o conjunto constituído por unidades políticas que mantêm relações regulares entre si e que são suscetíveis de entrar numa guerra geral, que tem como característica primordial [...] a configuração das relações de forças (Aron, 1986, p. 153, 154; cf. 1985).

Essa definição nos permite iniciar a compreensão do problema em toda a sua dimensão. Somos obrigados a admitir que é limitada, pois está condicionada por uma época em que os atores das relações internacionais são apenas as unidades políticas e as relações são prioritariamente as relações de poder. O próprio Aron conseguiu uma grande proeza para o entendimento do fenômeno e para a tentativa de dar autonomia à disciplina ao colocar todos os tipos de relações que se dão dentro sistema internacional a reboque da política internacional. Contudo, à medida que o tempo transcorria, sua teoria pare- 
cia ficar datada, seja pela exclusividade do ator, seja pelo fato de seu conceito de sistema ser definido em função desse único tipo de ator. Mas podemos tentar desdobrá-lo e destrinchar as partes que o compõem, para produzirmos um conceito de sistema internacional mais elástico e adequado para interpretar a realidade ao longo do tempo, principalmente acrescentando novos atores.

Percebemos pela definição anterior alguns elementos que poderiam reordenar o conceito da seguinte forma: sistema internacional é um conjunto composto por unidades políticas em interação, que apresentam um certo posicionamento no sistema, que se pode alterar e é suscetível de entrar em guerra geral. Mas, antes de explicar as suas partes poderíamos interrogar: é possível estender a definição a ponto de ser possível um quadro amplo para dar conta da realidade contemporânea em que os atores são variados e possa também ser aplicada à interpretação da sucessão histórica das relações internacionais? Tentaremos apresentá-la.

\section{Podemos conceber um sistema internacional como}

Um conjunto composto por atores em interação, cujo principal tipo de ator é a unidade política, existindo hierarquia de poder entre elas, o que define um posicionamento no sistema. As mais poderosas unidades políticas - com uma certa participação ou influência de alguns outros atores, como as corporações multinacionais e as instituições transnacionais - organizarão as relações internacionais, definindo zonas de influência que, no limite, constituem grupos de alianças, sejam políticas, econômicas ou militares, ou uma mistura das três. Elas também definem as formas de atuação dos demais atores, delimitando seus espaços de atuação à medida que recuam no seu poder de ação. Como o sistema vive em equilíbrio dinâmico, ao longo do tempo sucedem-se alterações nesse posicionamento das unidades políticas, devido ao aumento ou perda de seus poderes relativos, o que modifica as relações entre elas no interesse de preservar o equilíbrio. Pode ocorrer, contudo, que esse equilíbrio seja rompido levando todas as principais unidades políticas a entrarem em confronto armado, arrastando consigo as demais unidades políticas, bem como os demais atores, e produzindo uma guerra geral que decretará o fim desse sistema e produzirá outro. Ou seja, a guerra geral, leva ao envolvimento de todos os atores, por isso surgirá uma nova relação, configurando novas regras de relacionamento (Suano, 2003).

Torna-se necessário explicar as partes que constituem essa definição. Os elementos chaves são: (1) conjunto composto por atores, explicando-se as 
razões de a unidade política ser o principal tipo de ator; (2) posicionamento; (3) por qual razão as mais poderosas unidades políticas regulam o sistema; (4) alteração no posicionamento; (5) modificação nas relações entre as demais unidades políticas e (6) guerra geral.

Resumidamente, (1) podemos dizer que o conjunto de atores compõe-se de uma estrutura com autonomia, não se resumindo a somatória dos elementos que o constituem. $\mathrm{O}$ que possibilita a existência de um conjunto são certos determinantes físicos e geográficos, científico e tecnológicos, além de políticos e culturais, definindo e estabelecendo certos elementos comuns que condicionam as interações entre as unidades políticos e a seu reboque entre os demais gêneros de atores. São esses condicionamentos que tornam viável a formação de um sistema. Por exemplo, no século V a.C. seria impossível a constituição de um sistema internacional que envolvesse as unidades políticas do extremo oriente e da península grega. A geografia, a tecnologia e a cultura não permitiriam.

Com relação ao fato de as unidades políticas serem o principal ator traznos uma série de questões. Primeiro, revela que os problemas relativos ao poder apresentam-se como centrais nas relações internacionais. No limite, não se pode desconsiderar essa dimensão das relações humanas. Admite-se que esse fator é central principalmente nas teorias realistas das relações internacionais. Não se ignora que essa escola constrói uma teoria com base na competição entre as unidades políticas desprezando os elementos de cooperação. Da mesma forma que também não se ignora que a cooperação se tem mostrado como fato presente nas relações políticas, sociais e humanas, bem como fator estruturador das relações sociais e internacionais, mas, o condicionante das relações de poder, de uma perspectiva dos interesses individuais tem-se apresentado como essencial ao pensamento das relações internacionais, principalmente nas buscas de autonomia para o estudo do fenômeno.

Essa condição permite-nos compreender o sentido do (2) posicionamento entre as unidades políticas nas relações internacionais, algo ligado à hierarquia de poderes entre as unidades políticas de uma determinada época. A especificação de uma época é crucial para que se possa configurar adequadamente o poder em um sistema, definir aquilo em que consiste e como pode ser observado, ou avaliado. 
Visto abstratamente, (3) o poder é normalmente entendido como a capacidade de um indivíduo impor sua vontade a um terceiro, sem ter uma contraposição significativa por parte daquele está sendo submetido. Parece-nos intuitivo que o poder se apresenta por meio de instrumentos concretos possuídos pelos elementos que estão em relação. Ao longo da história observouse que o instrumento militar foi o mais adequado, pois a força física se mostrava como a mais garantida forma de submissão da vontade do outro. Por isso, normalmente afirmava-se que a dimensão do poder que determinava a posição hierárquica no sistema internacional era a capacidade de fazer a guerra.

Hoje, (4) observa-se que graças a presença e influência dos novos tipos de atores, as mudanças ocorridas na estrutura produtiva e, por isso, também graças a atual posição assumida pela economia, apenas a capacidade militar não pode ser o determinante para definir o posicionamento hierárquico. $\mathrm{O}$ aspecto militar passa a ser apenas um dos fatores, juntamente com a economia, que muitos teóricos têm considerado como sendo o primordial, algo que é muito discutível.

A idéia de posicionamento mostra-se, assim, como essencial para entender a noção de sistema internacional, uma vez que, embora se tenha como clara a condição anárquica do relacionamento entre os atores, percebe-se que seu relacionamento não é caótico, pois há regras que orientam o comportamento de todos os sujeitos no espaço internacional. Tais condições reguladores surgem do relacionamento entre as grandes unidades políticas. Elas determinam a realidade do sistema, cabendo as menores unidades o papel de descobrir formas de sobrevivência, adaptando-se às condições impostas.

Da compreensão dessa idéia podemos passar ao entendimento de que (5) a mudança de posicionamento leva a uma modificação nas relações entre as demais unidades. O simples fato de se alterar o poder de uma unidade afetará as condições de ação dos atores imediatamente relacionados, obrigando-os a mudar sua postura em relação à potência emergente, no caso de aumento de poder, ou para ocupar o vácuo de poder causado pela unidade decadente. Deve-se ressaltar que há alterações de posicionamento que são significativas para o sistema como um todo, outras trazem importância apenas para o subsistema no qual estão inseridas, sem incidir em qualquer mudança significativa para a ordem internacional. 
Outra questão que vem a tona acerca das regras que são estabelecidas diz respeito a como essas regras são constituídas. O surgimento de um sistema internacional só pode ser concebido na medida em que os grandes se apresentam no cenário internacional. Imediatamente, constituem-se espaços políticos que são apropriados por eles definindo uma área exclusiva sua. São zonas de influência, aquelas regiões políticas vitais para a consecução dos interesses dos grandes atores. Normalmente, perceberíamos como sendo aquela região geográfica imediatamente próxima a potência, mas em realidade a coincidência geográfica com a zona de influência é fortuita. Ela corresponde, em realidade ao espaço geográfico em que a projeção de poder de uma grande potência oferece resistência que tenda a zero, por isso acaba se confundindo com o conjunto de aliados que estão a reboque de um ator significativo, apoiando-o nessa projeção de poder, ou sobrevivendo às custas do apoio que recebe desse grande. Da imediata constituição de zonas de influência é que começam a se constituir regras informais de convivência, até serem estabelecidas as regras formais que, além das regras informais, determinarão o comportamento de todos os tipos de atores do sistema internacional. Por mais que, hoje, a estrutura da produção econômica mundial esteja reduzindo as barreiras das zonas de influência, esse fato ainda não se dissipou e, enquanto houver entes políticos que tenham ação autônoma no cenário internacional, ela será um produto do relacionamento entre eles ficando apenas no horizonte a concepção de um mundo que se constitua como uma sociedade global, dissolvendo a questão nas formas de relacionamento no sentido como se dão no interior de um Estado.

Finalizando, (6) observamos que o relacionamento entre os atores, determinado pelos relacionamentos entre as unidades políticas, pode ser extinto e substituído por outro modelo de relacionamento no caso de ocorrer um abalo no equilíbrio entre as unidades políticas e resultar numa guerra geral. Ela se define como "uma guerra que envolve todas as unidades do sistema", mas, nesse momento, devemos esclarecer alguns pontos.

A guerra geral só ocorre quando as grandes potências chegam a um impasse no choque de interesses e nos confrontos de suas projeções de poder. Não havendo solução negociada e pacífica entre elas, o último recurso será a guerra. Normalmente, pensando apenas em termos da lógica do poder militar e numa realidade com pouca interdependência econômica, um confronto entre uma grande potência e uma potência média, ou uma pequena potência 
não produz abalos ao sistema internacional, a menos que esta esteja sob a esfera de influência de um outro grande que irá ao último recurso para defender seus interesses e não o de seu aliado, é bom que isso fique claro. É relevante que se observe se aquela unidade que está sendo confrontada é, ou não, tão significativa a ponto de exigir uma resposta militar do seu aliado, ou protetor. Caso não seja, terá de responder por si própria no confronto militar. Isso significa que para uma guerra vir a ser uma guerra geral é necessário que os grandes entrem em conflito e que todos os grandes se vejam obrigados a participar da contenda, mesmo que não militarmente. Aí, sim, o sistema será levado a uma conflagração geral.

A importância desse conceito para a noção de sistema internacional se dá pelo fato de a conflagração de uma guerra geral significar a morte de um sistema e o nascimento de outro, permitindo-nos, inclusive, observar a história, da perspectiva da disciplina Relações internacionais, como a história da sucessão de sistemas, incluindo os passos para a constituição de um sistema com abrangência mundial e as suas transformações e substituições.

Fica-nos a dúvida quanto ao fato de essa concepção ser datada e não se aplicar à realidade contemporânea. Hoje, seria possível uma guerra geral? Pensando na realidade de interdependência econômica que existe atualmente, observa-se que a possibilidade de uma guerra geral teria de levar em conta um grande número de variáveis. Principalmente, seríamos obrigados a avaliar qual a autonomia que as unidades políticas tem, hoje, para buscar seus interesses sem levar em conta as demais unidades, além de uma certa demanda de outros atores, principalmente as corporações multinacionais (Gonçalves, 2002), ou seja, teríamos de pensar em que medida uma unidade política pode agir sem ser constrangida pela estrutura do sistema internacional ${ }^{14}$ e por isso poder tomar decisões que abalem o equilíbrio do sistema internacional levando a um posicionamento das demais unidades e, a reboque, uma ação dos demais atores. O que se deve observar é se uma unidade política está ou não inserida na estrutura de produção mundial, e, estando, em que medida isso ocorre. Em função dessa espécie de escala é que poderíamos admitir a guerra entre as unidades políticas, no caso entre um grande e um pequeno e, talvez, entre grandes para defender um aliado seu que foi atacado. Contudo, parece-

14 Para maiores esclarecimentos sobre as teorias que tratam das relações que se dão entre atores e estruturas, consultar: Dougherty e Pfaltzgraff Jr. (2003, cap. 2-4). 
nos que as relações de custo e benefício tendem a tornar difícil uma guerra geral no mundo contemporâneo, embora não impossível, em função do enrijecimento causado pelo pós-11 de setembro.

Não se deve, neste instante, discutir se tal forma de conceber o fenômeno relações internacionais e o conceito de sistema internacional estão inscritos em um suposto "programa realista das relações internacionais". ${ }^{15}$ Isto exigiria um espaço que vai além do exigido ao artigo. Deve-se apenas adotar o procedimento de abordar o fenômeno com os fatos e características que são identificados para realizar as reflexões que possam nortear uma ação racional em relações internacionais, deixando para um outro lugar e momento a questão de supostas filiações.

Realizados esses esclarecimentos podemos efetuar um outro salto teórico em direção à questões que propusemos no início do artigo: que tipo de discurso está sendo realizado quando alguém se pronuncia acerca de problemas da área.

\section{Finalizando: a questão dos discursos}

Observando-se os problemas e os conceitos que foram identificados, percebemos que os especialistas em relações internacionais realizam tipos de reflexão diversas quando estudam e analisam o fenômeno e se pronunciam acerca dele. Podemos dizer que são instâncias distintas do discurso que precisamos compreender levando-se em conta o papel exercido pelo indivíduo que o enuncia.

Parece-nos transparente, também, que há uma diferenciação nítida entre o universo teórico e o universo prático. Uma diferenciação entre aquele intelectual que se expressa explicando o fenômeno, ou um fato que se dá no seu âmbito, e aquele agente que faz as relações internacionais, independentemente do que, ou de quem ele esteja representando. Eis algo que deveria ser transparente, contudo não é o que ocorre. Talvez porque os agentes, representantes dos atores das relações internacionais, necessitam apresentar ou usar

15 Para maiores esclarecimentos acerca da noção de programa de pesquisa, consultar: Chaumers (1993). Para maiores esclarecimentos sobre a aplicação do conceito de programa de pesquisa nas Relações Internacionais, especificamente na teoria realista, consultar: Chiappin (1994). 
corpos doutrinários amplos para justificar certos procedimentos que são obrigados a adotar e alguns acabam concebendo uma explicação da realidade internacional, apresentando-a como uma teoria explicativa do fenômeno como um todo.

Isso ocorre pelo fato de a área estar intimamente relacionada com a política, logo relacionada da mesma forma e intensidade com o poder, o que nos obriga, para não cometer erros de interpretação, a tomar um posicionamento semelhante ao adotado por Max Weber e admitir que há duas vocações também em relações internacionais: uma científica e outra prática, com comportamentos e percepções bem diferentes, embora, normalmente, se exija e seja dado ao homem da ação um status teórico que normalmente não se exige, ou se atribui ao político comum. Razão pela qual acabamos consultando os estadistas tanto quanto os estudiosos quando queremos entender o fenômeno internacional, ou uma teoria.

Assim, acabou-se por abrir uma janela pela qual se possa olhar e a solução transita pela espécie de homem de ação das relações internacionais. Quando ele é representante dos tipos de atores não estatais, normalmente é um técnico, um profissional especializado, conhecedor de questões teóricas e, geralmente, um intelectual. Quando é representante das unidades políticas, embora um homem preocupado com o poder, suas concepções não podem estar direcionadas para as questões corriqueiras, uma vez que ao atuar não luta apenas pelos seus interesses, ou do seu grupo, ou da sua sociedade, ele é obrigado a pensar no âmbito da sobrevivência e expansão das instituições que constituem o Estado que representa. Não pode pensar apenas os valores e as questões sociais, mas, principalmente, as "questões de Estado". Como diria Max Weber sua ética é a da responsabilidade, não a da convicção (Weber, 1982). Por isso, comumente, quando se pronunciam e apresentam teorias, elas são grandes justificativas ideológicas para as políticas externas dos Estados que representam, ou representaram. Casos bem interessantes são os de Huntington, com o seu artigo e posterior livro sobre o Choque de Civilizações (Suano, 2003. p. 61-84), e o de Fukuyama, não apenas com o seu artigo e livro sobre o "fim da história", mas, bem mais interessante, o último livro lançado, intitulado "Construção de Estados". ${ }^{16}$

16 Não seria ilegítimo dizer que aí temos uma boa justificativa teórica para a política externa do EUA, sob o governo de George W. Bush. 
O que temos diante de nós, então, são dois universos diferentes: há o universo dos políticos, que chegam a constituir doutrinas, e há o dos teóricos, cujos discursos são realizados por acadêmicos. Não cabe avaliá-los se são superiores uns aos outros, mas apenas tentar entender as diferenças, pois em realidade existem quatro tipos de discursos com uma distância significativa entre eles: o teórico; o doutrinário; o ideológico e o analítico. Eles podem ser emitidos pelo mesmo agente, mas têm intenções distintas e são momentos diversos. $^{17}$

Pode-se dizer que os discursos teóricos, ${ }^{18}$ são aqueles que objetivam apresentar uma explicação para o fenômeno relações internacionais, mostrando como ele se constrói e quais suas formas de articulação. Ele concebe uma explicação das relações internacionais, criando ou adotando conceitos e articulando-os de maneira que torne racionais os múltiplos fatores que definem e interferem nas relações entre os atores. Objetiva esclarecer as interações entre os próprios fatores, bem como entre eles e os atores que são considerados relevantes para a constituição das relações internacionais. Isso torna possível identificar as condições propiciadoras de um equilíbrio que preserve tais relações ao longo do tempo.

É necessário entender no que se constituem os discursos teóricos pelo fato de eles estarem situados no nível mais alto de abstração. São os instrumentos que permitem compreender a realidade internacional. De outra maneira, são as lentes pelas quais é possível observar racionalmente a realidade.

Já os discursos dos representantes dos atores não têm essa abrangência, uma vez que transitam no espaço concreto do fenômeno. Em realidade eles apropriam-se de um conteúdo teórico qualquer para conceber suas doutrinas, expressar suas justificativas e adotar uma "Weltanschaung" que os apoie na formulação de suas estratégias de ação e, no caso dos representantes estatais, formular, ou executar as políticas externas. Afinal, as teorias das relações

17 Pensando em qual profissional apresentaria cada um desses discursos, poderíamos dizer que, normalmente, o primeiro discurso é emitido pelos acadêmicos, professores e pesquisadores; o segundo, pelos formuladores de política externa; o terceiro, por assessores governamentais e de organizações; e, o quarto, por consultores. Contudo, não se pode estabelecer uma divisão tão rígida, havendo uma grande sobreposição e confusão acerca de quem faz o que, principalmente no Brasil.

18 Como já foi dito, pronunciados primordialmente por estudiosos, profissionais acadêmicos que têm a pretensão de mostrar o fenômeno em si. 
internacionais permitem a apreensão de elementos que são essenciais para a tomada de decisão, pois possibilitam: (1) fixar conceitos que propiciem um instrumento para abordar a realidade tornando-a racional; (2) entender a história de uma perspectiva globalizante, utilizando conceitos que levam em conta a esfera internacional; (3) conceber a dinâmica do mundo em que se vive; (4) equacionar os problemas que se colocam diante do analista; (5) buscar uma lógica que auxilie na compreensão dos atores no sistema e (6) produzir instrumentos para auxiliar na previsão de ações dos atores no cenário internacional.

Entendendo o teórico da forma como foi apresentado, podemos partir para a compreensão dos demais discursos. Normalmente, o discurso doutrinário é pronunciado pelos estrategistas ou formuladores de políticas externas, ${ }^{19}$ uma espécie de profissional que tem a pretensão de estabelecer as diretrizes que devem ser adotadas por determinado ator, na condução de suas relações com os demais atores dos sistemas internacionais. ${ }^{20}$

Como está na própria idéia de doutrina: são discursos voltados para definir etapas da ação. Colocam-se como definidores dos passos que devem ser dados para alcançar os objetivos estabelecidos pelos atores, por meio de seus representantes. Quase sempre uma doutrina é expressa juntamente com a estratégia adotada por uma unidade política para alcançar seus objetivos no cenário internacional. Hoje, devido a autonomia adquirida pelos demais atores, percebemos que o mesmo raciocínio se aplica aos representantes de corporações multinacionais, ONGs e Organizações Internacionais. Também apresentam estratégias de ação e doutrinas que justificam seus comportamentos.

19 Deve-se entender política externa como a formulação das atitudes de uma unidade política, diante das demais unidades políticas. Isso exige: conhecimento do cenário interno; conhecimento do cenário externo; formulação de uma agenda que defina os objetivos de longo prazo e os objetivos de curto prazo.

20

No escopo dos formuladores de política externa é possível colocar um tipo de profissional que tem sido posto em evidência ultimamente: o diplomata empresarial. É uma questão de fazer analogia entre o trabalho realizado por agentes estatais e governamentais para buscar os interesses de uma determinada unidade política, sejam quadros do executivo, sejam diplomatas de carreira que executam a política externa de um Estado, com o trabalho desses assessores que buscam os interesses dos demais atores corporativos, ou institucionais. 
Podemos afirmar ainda que uma doutrina pode ser vista como uma espécie de aplicação de uma teoria, mesmo porque o ato de adotar uma corrente teórica implica todo um conjunto de crenças acerca da existência do mundo, da natureza humana e dos comportamentos derivados dessa realidade. Por exemplo, estratégias de ação que se baseiam na concepção realista das relações internacionais estarão sempre vinculadas às noções de segurança, poder, política do poder, maximização da força, competição, conflito etc. Ao contrário, aquelas vinculadas aos outrora denominados idealistas, hoje chamados de liberais-institucionalistas, priorizam as instituições transnacionais, a solução pacífica dos conflitos, a cooperação, em síntese, a construção de um mundo integrado, ao invés de dividido e conflituoso.

Nesse sentido, o que melhor se pode adquirir de uma doutrina são os passos adotados por um determinado ator e a identificação da escola teórica à qual está vinculado, ou estão vinculados os seus construtores. De forma mais explícita, elas podem ser vistas como desdobramentos de uma teoria, uma aplicação sua no mundo concreto. É óbvio que os teóricos pretendem que sua explicação apresente a realidade tal como ela é, já os doutrinadores não estão preocupados em explicar o mundo, mas sim em dizer como agir, admitindose que o mundo é da forma como está explicada pela Weltanschaung da qual comunga, sem ter a pretensão de questioná-la, muito menos de desenvolvê-la.

Diferentemente deve ser entendido o discurso ideológico. Surge com a pretensão científica de ser a explicação do mundo tal como ele é, apresentando um quadro que objetiva equacionar os problemas das relações internacionais em determinado momento, dando conta de incorporar os novos fatos que uma teoria anterior não explicava, ou não previa. Entretanto, quase sempre são discursos que visam justificar a ação de um determinado ator, prenunciar uma doutrina, ou explicar a dinâmica da realidade, mostrando-se como uma filosofia da história. O problema está em como perceber quando um discurso é meramente ideológico, pois alguns são tão elaborados e tem um grau de complexidade e acabamento tão rico que se mostra mito tênue a linha que o distingue do discurso teórico stricto sensu. Só é possível percebê-lo quando se consegue identificar a pretensão daquele que o enuncia.

Por exemplo, quando Francis Fukuyama apresentou sua tese do "fim da história", vários estudiosos perceberam que ali estava mais uma grande defesa da democracia liberal, que uma teoria das relações internacionais, no en- 
tanto, na época não se percebeu que aquela tese poderia ser usada para defender a globalização econômica como entendida pelos anglo-saxões, em função da dinâmica do capitalismo mundial naquele instante. Era uma tese que caía como uma luva. De forma análoga poderia ser entendida a tese do "choque de civilizações" de Samuel Huntington. Ali está muito bem definido que mais importante que a nova realidade do mundo contemporâneo é a manutenção da liderança americana do bloco ocidental. Isso está explícito. Ambos têm como objetivo primordial defender posicionamentos, políticas externas, conceber doutrinas e, para tal, apresentaram uma explicação do mundo que justificava sua postura. Essa é a pretensão do discurso ideológico que, no limite, prescreve ou defende a necessidade de adoção de certas doutrinas e aplicação de determinadas políticas externas.

Finalizando, podemos passar para a compreensão do último discurso, o analítico. É o discurso técnico, do analista de conjuntura, aquele profissional que utiliza uma teoria específica das Relações Internacionais, e adota uma perspectiva para entender as relações que se dão entre atores e indicar possíveis ações futuras dos atores analisados em um cenário construído, e a quem se atribui a função de assessorar quadros governamentais, informar, ou auxiliar os formuladores de política externa, os dirigentes e agentes de quaisquer tipos de atores que necessitam de especialistas capacitados em explicar uma determinada situação do mundo contemporâneo.

O que fazem é uma análise da conjuntura internacional - normalmente política -, ou seja, apresentam uma forma de entender as relações que se dão entre atores no sistema internacional atual, adotando uma perspectiva teórica e centralizando as atenções em um determinado tema, e/ou determinada região, e/ou determinado ator, construindo um cenário no qual seja possível compreender as formas de diálogo, as interdependências, as alianças, os conflitos, as estratégias e/ou políticas externas adotadas e possibilite indicar possíveis ações futuras dos atores analisados em circunstâncias precisas.

O discurso analítico não tem o desejo de dizer como se deve entender o fenômeno relações internacionais, qual é a sua natureza, conceber uma doutrina e muito menos justificar uma política externa. Seu objetivo é explicar as razões pelas quais os comportamentos ocorrem da forma como se dão. Assim, os discursos analíticos pretendem se apresentar como os mais profissionais de todos, pois visam explicar uma situação em um determinado momen- 
to, mesmo que muitas vezes se vejam obrigados a recorrer à história para dizer como ela se originou. É evidente sua pretensão de neutralidade axiológica, embora saibamos que ela é impossível, mesmo porque, ao realizar uma análise, o profissional se vê obrigado a adotar uma teoria, ou como instrumento, ou como pano de fundo para conectar os fatos conjunturais explicando-os de acordo com as variáveis e atores isolados.

A existência dessas instâncias do discurso é um fato do dia-a-dia do profissional em Relações Internacionais e a sua compreensão é primordial para o desenvolvimento do campo, pois mostra-nos a complexidade de uma disciplina que ainda vive graves problemas epistemológicos, mas que podem ser solucionados ao longo de um trabalho cumulativo se os especialistas tiverem clareza do universo em que estão transitando.

Podemos afirmar que o discurso teórico é o mais importante e aquele que tem propiciado maior beleza à luta pela autonomia da ciência Relações Internacionais, mas ele não é o único que tem permitido o seu alargamento e a conquista de espaços, por meio do trabalho típico do pesquisador. A maioria dos profissionais tem percebido que não é nesse trabalho que está o principal foco dos especialistas na área. Ainda é no discurso técnico, o discurso daquele profissional que realiza as análises de conjuntura do campo internacional que temos o grosso das produções e é nesse setor que os profissionais precisam centrar esforços para despertar no mercado a necessidade de um especialista que será imprescindível no século XXI.

Nas quatro últimas décadas do segundo milênio, quando o mundo começou a se mostrar tão diminuto, com acontecimentos em regiões distantes refletindo-se automaticamente nos jardins das nossas casas, a ciência RI começou a nos lembrar a Sociologia, quando surgia nas quatro últimas décadas do século XIX: lutava por autonomizar-se, adquirindo uma configuração sua, e tinha a pretensão de explicar a ordem, para preservar o equilíbrio social. Não é ilegítimo afirmar que ela tem a mesma pretensão, ficando em aberto se objetiva ter um escopo de uma sociologia ampliada, ou pretende a criação de uma maneira diversa de compreender a realidade, construir a paz e conceber uma ordem plural entre os sujeitos no espaço internacional.

Deve-se acrescentar ainda que, embora não seja possível tratar de forma desenvolvida neste artigo a questão do campo profissional, este é para nós um dos problemas mais relevantes na atualidade. Pouco se divulgam informações 
sobre o que é um internacionalista, ficando a ilusão para o mercado de que sua tarefa é idêntica à realizada pelo profissional de Comércio Exterior. Também tem sido reduzido o seu esforço a um trabalho que pode ser executado por vários outros profissionais de ciências humanas, tais como juristas, economistas, sociólogos, antropólogos, historiadores etc., o que não é o caso. Talvez, uma grande parcela de responsabilidade por essa confusão se deva à maneira como são organizados os cursos de relações internacionais no Brasil e a forma como são concebidos os conteúdos das disciplinas, que acabam formando generalistas desvinculados do real universo de atuação desse profissional. Mas, também terá de ficar aberto como se configura o trabalho de um internacionalista, uma vez que está fora do escopo deste artigo.

\section{Referências}

ARON, Raymond. Paz e guerra entre as nações. Brasília: UnB, 1986. . Estudos políticos. Terceira Parte. Brasília: UnB, 1985.

BOBBIO, Norberto; PASQUINO, Gianfranco; MATTEUCCI, Nicola. Dicionário de Política. Brasília: UnB, 1983.

- Estado, governo e sociedade: para uma teoria geral da política. São Paulo: Paz e Terra, 1990.

BRAILLARD, Philippe. Teorias das Relações Internacionais. Lisboa: Fundação Calouste Gulbenkian, 1990.

CARR, Edmond H. Vinte anos de crise. Brasília: UnB, 2001.

CHAUMERS, A. F. O que é a ciência afinal? São Paulo: Brasiliense, 1993.

CHIAPPIN, Joseph R. N. O paradigma de Huntington e o realismo político. Lua Nova, São Paulo, n. 34, 1994.

COLUMBUS, Theodore. Introduction to International Relations: power and justice. 3. ed., New Jersey: Pratice Hall Inc. Englewood Cliffs, 1986.

DOUGHERTY, J. E.; PFALTZGARFF JR., R. L. Relações Internacionais: as teorias em confronto. Lisboa: Gradiva, 2003.

FUKUYAMA, Francis. Construção de estados: governo e organização no século XXI. Rio de Janeiro: Rocco, 2004.

GONÇALVES, Williams. Relações Internacionais. Rio de Janeiro: Jorge Zahar Editor, 2002. 
GRIFFITHS, M. 50 grandes estrategistas das Relações Internacionais. São Paulo: Contexto, 2004.

HEMPEL, C. G. Explicação científica. In: MORGENBESSER, S. (org.). Filosofia da ciência. São Paulo: Cultrix, 1972.

KEOHANE, Robert. Soberania estatal e instituições multilaterais: resposta à interdependência assimétrica. In: MOISÉS, José Alvaro? (org.). O futuro do Brasil: a América Latina e o fim da guerra fria. Rio de Janeiro: Paz e Terra, 1992, p. 165-191.

MERLE, Marcel. Sociologia das Relações Internacionais. Brasília: UnB, 1981.

MOREIRA, Adriano. Teoria das Relações Internacionais. 4. ed., Coimbra: Almedina, 2002.

MORGENTHAU, Hans. Politica entre las naciones, Buenos Aires: Grupo Editor Latinoamericano, 1986.

NAGEL, E. Ciência: Natureza e objeto. In: MORGENBESSER, S. (org.). Filosofia da Ciência. São Paulo: Cultrix, 1972.

NYE Jr., J. S. Compreender os conflitos internacionais. Lisboa: Gradiva, 2002.

SANTOS, Theotônio dos. A teoria da dependência: balanço e perspectivas. Rio de Janeiro: Civilização Brasileira, 2000.

SARTORI, Giovanni. A politica. Brasília: UnB, 1994.

SKLAIR, L. Sociologia do sistema global. Petrópolis: Vozes, 1995.

SOUZA, H. J. (BETINHO). Como se faz análise de conjuntura. 25. ed. São Paulo: Vozes, 2004.

SUANO, Marcelo J. F. A identificação dos interesses estratégicos norte-americanos e o surgimento de uma nova estratégia da contenção - uma releitura de Samuel Huntington em busca do verdadeiro oponente dos EUA. In: Prisma Jurídico. São Paulo, v. 2, p. 61-84, set. 2003.

VIZENTINI, Paulo Fagundes. Relações Internacionais: um balanço teóricohistoriográfico. In: TEIXEIRA DA SILVA, Francisco Carlos (org.). O século sombrio: uma história geral do século XX. São Paulo: Campus, 2004.

WALTZ, Kenneth. N. O homem, o estado e a guerra. São Paulo: Martins Fontes, 2004.

Teoria das Relações Internacionais: trajectos. Lisboa: Gradiva, 2002.

WEBER, Max. Ciência e política: duas vocações. São Paulo: Cultrix, 1982.

Recebido em 20 de janeiro de 2005 e aprovado em 20 de julho de 2005 